\title{
Sob um olhar crítico: o acolhimento institucional da criança e do adolescente indígena
}

\author{
Under a critical eye: the institutional reception of the indigenous children and adolecents
}

\begin{abstract}
Dessica Padilha Duarte
Graduada em Direito pela UniRitter. Advogada jessica_padilhaduarte@hotmail.com

Michelle Alves Monteiro

Mestranda em Direito Público - UNISINOS, bolsista CAPES

Advogada do Serviço de Assessoria Jurídica às comunidades indígenas e quilombolas da Universidade Federal do Rio Grande do Sul - SAJU/UFRGS michelle_monteiro@terra.com.br
\end{abstract}

(iD) Tatiana de A. F. R. Cardoso Squeff

Doutora em Direito Internacional pela UFRGS/PPGD, com período sanduíche junto a University of Ottawa. Professora permanente do Programa de Pós-Graduação em Direito da Universidade Federal de Uberlândia, onde também atua como professora adjunta de Direito Internacional tatiafrcardoso@gmail.com

Resumo: Esse artigo tem como objetivo apresentar o instituto do acolhimento institucional de crianças e adolescentes indígenas em situações de risco e vulnerabilidade social, analisando, para tanto, o contexto que leva à intervenção estatal, bem como o modo como são tratadas nas instituições de acolhimento, buscando confirmar que as especificidades culturais não são respeitadas e, muito menos, consideradas quando existe a necessidade de intervenção, dentro de um sistema jurídico que possui um viés colonialista. Logo, pautando-se pelo método dedutivo, através de uma pesquisa crítico-descritiva, pretende-se abordar o referido instituto, demonstrando por meio de um levantamento bibliográfico, documental e jurisprudencial qualitativo-localizado, o porquê e como ocorre o acolhimento institucional de crianças e adolescentes indígenas para, então, abordar as especificidades de casos envolvendo tal prática no Brasil. Ao cabo, conclui-se que é evidente a existência de violações às legislações que protegem as crianças e adolescentes, bem como às normas que resguardam a cultura indígena no Brasil, resultando na anulação cultural desses povos no país.

Palavras-chave: acolhimento institucional; crianças e adolescentes indígenas; anulação cultural.

Abstract: This article intends to present the institutional reception of indigenous children and adolescents in situations of risk and social vulnerability principle; analyzing, to this end, the context that leads to state intervention, as well as the treatment conferred to them in State-institutions, seeking to confirm that cultural specificities are not respected and, much less, considered when intervention seems needed within a legal system with a colonialist bias. Therefore, based on the deductive method and through a critical-descriptive research, carried out though a qualitative-localized bibliographical, documentary and jurisprudential survey, this article aims at detailing the said principle, demonstrating the reasons for the occurrence of indigenous children and adolescents' institutionalization, and the specificities of cases involving such practice in Brazil. At the end, the conclusion is that the norms that protect children and adolescents in Brazil as well as those that protect the indigenous culture are evidently violated, leading to the cultural annulment of these peoples in the country.

Keywords: institutional reception; indigenous children and adolescents; cultural annulment. 


\section{Para citar este artigo}

ABNT NBR 6023:2018

DUARTE, Jessica Padilha; MONTEIRO, Michelle Alves; SQUEFF, Tatiana de A. F. R. Sob um olhar crítico: o acolhimento institucional da criança e do adolescente indígena. Prisma Jurídico, São Paulo, v. 20, n. 1, p. 36-56, jan./jun. 2021. http://doi.org/10.5585/prismaj.v20n1.11335.

\section{Introdução}

$\mathrm{Na}$ tentativa de prestar auxílio a crianças e adolescentes em situação de violação de direitos, tais como abandono, negligência e violência, a legislação brasileira estipula medidas que visam à sua proteção, tal como a realização do acolhimento institucional - uma ação provisória e excepcional que tem como escopo não só reduzir a situação de vulnerabilidade em que elas se encontram, como também fomentar o seu desenvolvimento cognitivo, social e afetivo, prestando um acompanhamento individual até que seja possível que retornem à sua família ou sejam encaminhados a um lar substituto (FONSECA, 2017). Diversos estudos publicados no país ao longo dos anos ressaltam a importância de tal medida (CNMP, 2013; 2016), em especial pela idade tenra e pelas violações sofridas por grande parte dos acolhidos.

Entretanto, um ponto essencial a ser pensado é justamente se tal medida seria a melhor alternativa quando aplicada a crianças e adolescentes indígenas, justamente por uma questão cultural, na medida em que a sua realocação, apesar de teoricamente depender da análise de diversos fatores, que variam desde a idade e o perfil de desenvolvimento até aspectos históricosociais da vida ${ }^{1}$, por vezes, termina por não permitir que eles se desenvolvam dentro de suas tradições e costumes quando acolhidos, conduzindo-os a mais uma violação de seus direitos basilares e até mesmo à sua exclusão da própria comunidade.

Logo, à luz dessa situação, este artigo tem como objetivo apresentar o instituto do acolhimento institucional de crianças e adolescentes indígenas em situação de risco e vulnerabilidade social, analisando, para tanto, o contexto que leva à intervenção estatal, bem como o modo de tratamento nas instituições de acolhimento, a fim de que se possa demonstrar que, em verdade, as especificidades culturais não são respeitadas e muito menos consideradas quando existe, dentro de um sistema jurídico que possui um viés branco, ocidental, colonialista, a necessidade de intervenção.

\footnotetext{
${ }^{1}$ De maneira geral, esses critérios advêm da análise do art. 92 do Estatuto da Criança e do Adolescente, in verbis: Art. 92. As entidades que desenvolvam programas de acolhimento familiar ou institucional deverão adotar os seguintes princípios: I - preservação dos vínculos familiares e promoção da reintegração familiar; II - integração em família substituta, quando esgotados os recursos de manutenção na família natural ou extensa; III - atendimento personalizado e em pequenos grupos; IV - desenvolvimento de atividades em regime de co-educação; V - não desmembramento de grupos de irmãos; VI - evitar, sempre que possível, a transferência para outras entidades de crianças e adolescentes abrigados; VII - participação na vida da comunidade local; VIII - preparação gradativa para o desligamento; IX - participação de pessoas da comunidade no processo educativo. (BRASIL, 1990).
} 
Desta feita, o estudo será dividido em três partes. Na primeira, serão abordados os princípios que regem o ECA, especificando o sujeito que se pretende proteger, a aplicação da medida de proteção de acolhimento institucional de forma geral e suas consequências. Na sequência, far-se-á uma pequena contextualização acerca da questão indígena no Brasil, seguida de uma análise sobre a aplicação do acolhimento institucional a crianças e adolescentes indígenas, apontando-se as violações ao artigo $28, \S 6^{\circ}$, do ECA, além de outros instrumentos normativos, como a própria Constituição, a partir de casos.

Por fim, para que seja efetivada uma análise da problemática de intervenção do Estado no acolhimento institucional de crianças e adolescentes indígenas, seguindo o método dedutivo, será realizada pesquisa de natureza aplicada e com um viés crítico-descritivo acerca do instituto, utilizando-se de um levantamento bibliográfico, documental e jurisprudencial sobre o tema, seguindo um recorte qualitativo quanto a essas fontes e limitado ao cenário brasileiro, a fim de que seja possível um maior entendimento sobre o tema, verificando-se, ao cabo, se há de fato uma desconsideração no país do respeito às tradições culturais nos casos de acolhimento que culminam em práticas assimilacionistas/anulatórias.

\section{$1 \mathrm{O}$ acolhimento institucional de crianças e adolescentes}

O Estatuto da Criança e do Adolescente (ECA), Lei Federal n. 8.069/1990, é uma legislação infraconstitucional, cuja edificação decorreu dos artigos 227 e 228 da Constituição Federal de $1988^{2}$ e que tem como objetivo gerar o cumprimento da proteção de pessoas em idade compreendida entre zero e dezoito anos. Para tanto, o $\mathrm{ECA}^{3}$ considera como criança o indivíduo entre zero e doze anos incompletos; e adolescente, o indivíduo entre doze e dezoito anos (ISHIDA, 2010, p. 2). Para Barros, “o critério adotado pelo legislador é puramente cronológico, sem adentrar em distinções biológicas ou psicológicas” (BARROS, 2010, p. 23).

O princípio base de amparo aos direitos de crianças e adolescentes é o da 'proteção integral', que visa a atribuir garantias para além daquelas destinadas aos adultos, uma vez que crianças e adolescentes são considerados pessoas em condição peculiar de desenvolvimento e, nesse sentido, sua proteção deve ser assegurada não só pela família e o Estado, mas pela sociedade em geral (NUCCI, 2015, p. 6).

\footnotetext{
${ }^{2}$ Art. 227. É dever da família, da sociedade e do Estado assegurar à criança, ao adolescente e ao jovem, com absoluta prioridade, o direito à vida, à saúde, à alimentação, à educação, ao lazer, à profissionalização, à cultura, à dignidade, ao respeito, à liberdade e à convivência familiar e comunitária, além de colocá-los a salvo de toda forma de negligência, discriminação, exploração, violência, crueldade e opressão; Art. 228. São penalmente inimputáveis os menores de dezoito anos, sujeitos às normas da legislação especial. (BRASIL, 1998).

${ }^{3}$ Art. $2^{\circ}$ Considera-se criança, para os efeitos desta Lei, a pessoa até doze anos de idade incompletos, e adolescente aquela entre doze e dezoito anos de idade. (BRASIL, 1990).
} 
Nesta senda de proteção integral, o ECA estabelece em seu art. 98 as causas que configuram violação ou ameaça de direitos que ensejam a imediata intervenção do Estado, por intermédio de seus órgãos competentes, a fim de efetivar a proteção daqueles que ainda não completaram 18 anos, com especial foco na situação de vulnerabilidade em que estão inseridos (NUCCI, 2015, p. 315). Logo, configura-se como ponto de partida para a identificação de situações que justificam a aplicação de medidas de proteção. “Art. 98. As medidas de proteção à criança e ao adolescente são aplicáveis sempre que os direitos reconhecidos nesta Lei forem ameaçados ou violados: I - por ação ou omissão da sociedade ou do Estado; II - por falta, omissão ou abuso dos pais ou responsável; III - em razão de sua conduta.” (BRASIL, 1990).

A hipótese do inciso I refere-se à conduta inadequada da sociedade ou do Estado, enquanto a hipótese do inciso II trata da falta, omissão ou abuso dos pais. Já a hipótese do inciso III refere-se à própria conduta da criança ou adolescente, quando se coloca em risco (ISHIDA, 2010, p. 170-174). Na concepção de Dupret (2010, p. 141), o art. 98 do ECA estabelece as situações de risco a que podem estar expostas a criança e o adolescente, apresentando, em seguida, no seu art. 101, as medidas de proteção próprias para fazer cessar tais situações.

Nesse sentido, as medidas de proteção pressupõem a existência de uma avaliação que identifique a situação de ameaça ou violação de direitos de crianças e adolescentes, realizadas por meio de intervenções de agentes públicos na vida das famílias, crianças e adolescentes. Por esse motivo, devem ser aplicadas pela autoridade competente e se dar nos limites e de acordo com o regramento previsto nos princípios do art. 100 do ECA, o qual traz os elementos que orientam a aplicação da medida de proteção (CURY, 2010, p. 419-439).

Em sequência, o ECA expõe, em seu art. 101, o rol exemplificativo das medidas de proteção que podem ser aplicadas a qualquer criança e adolescente que se encontre em situação de risco. Dentre as medidas elencadas, tem-se, no inciso $\mathrm{VII}^{4}$, a previsão do Acolhimento Institucional, instituto que excepciona a regra e o direito da criança e do adolescente de serem criados no seio da família natural, uma vez que, quando de sua aplicação, a criança ou adolescente é retirado do ambiente familiar e comunitário em que está inserido.

$\mathrm{O}$ acolhimento institucional deve ser aplicado pela autoridade competente e consiste em encaminhar a criança ou o adolescente a instituição de acolhimento por motivo de abandono ou verificação de que a sua manutenção na família ou no ambiente de origem não seja a melhor alternativa para sua proteção. Essa medida deve ser mantida somente pelo tempo necessário, visando ao retorno do convívio familiar, seja para a família de origem ou substituta. Frisa-se

\footnotetext{
${ }^{4}$ Art. 101. Verificada qualquer das hipóteses previstas no art. 98, a autoridade competente poderá determinar, dentre outras, as seguintes medidas: [...] VII- acolhimento institucional; (redação dada pela Lei n 12.010 , de 2009) (BRASIL, 1990).
} 
que a obrigação das entidades de atendimento e dos órgãos competentes é a de investir todos os esforços a fim de efetivar a reintegração da criança e do adolescente à sua família ou, sendo constatada a impossibilidade de retorno, a sua colocação em família substituta (CARNEIRO, 2010, p. 532).

Neste contexto, para que ocorra o ingresso de crianças ou adolescentes em acolhimento institucional é obrigatória a emissão da guia de acolhimento, ressalvados os casos em que o acolhimento se dá de maneira excepcional e urgente, casos que a guia será emitida após a comunicação ao órgão judiciário. Para Nucci (2015, p. 347), a guia de acolhimento tem por objetivo "assegurar que exista um documento comprovando a inclusão da criança ou adolescente em regime de acolhimento". O citado autor refere, ainda, que a guia de acolhimento traz formalismo à medida e assegura que as autoridades competentes estejam cientes do acolhimento institucional e encaminhem uma solução ao caso.

Conforme $\S \S 4^{\circ}$ e $5^{\circ}$ do art. 101 do ECA (BRASIL, 1990), imediatamente após o acolhimento da criança ou adolescente, a entidade acolhedora deverá elaborar um Plano Individual de Atendimento (PIA), visando à reintegração familiar, salvo determinação judicial em contrário, caso em que deverá contemplar a colocação em família substituta. O PIA nada mais é do que um planejamento escrito preparado pelo setor técnico da unidade acolhedora. $\mathrm{Na}$ elaboração do plano, deverão ser levadas em conta a opinião da criança ou adolescente e realizada a oitiva dos pais ou responsáveis (ISHIDA, 2010, p. 189).

Cumpre registrar que, sendo o acolhimento institucional transitório para a reintegração familiar ou colocação em família substituta, o contato com a família de origem deve ser estimulado, razão pela qual o $\S 7^{\circ}$ do art. 101 do ECA (BRASIL, 1990) garante que o acolhimento ocorrerá no local mais próximo à residência dos pais ou responsáveis, bem como garante a inclusão da família em programas de orientação, apoio e promoção social para que seja possível a reintegração da criança ou adolescente (DUPRET, 2010, p. 147).

Não obstante, caso constatada a impossibilidade de retorno da criança ou do adolescente à família de origem, ainda que tenha sido realizado o encaminhamento da família para programas assistenciais, será elaborado um relatório fundamentado, constando a descrição das providências tomadas e a expressa recomendação pela destituição do poder familiar, tutela ou guarda (CURY, 2010, p. 461), de acordo com o $\S 9^{\circ}$ do art. $101^{5}$ do ECA.

\footnotetext{
5 Art. 101, § 9․․ Em sendo constatada a impossibilidade de reintegração da criança ou do adolescente à família de origem, após seu encaminhamento a programas oficiais ou comunitários de orientação, apoio e promoção social, será enviado relatório fundamentado ao Ministério Público, no qual conste a descrição pormenorizada das providências tomadas e a expressa recomendação, subscrita pelos técnicos da entidade ou responsáveis pela execução da política municipal de garantia do direito à convivência familiar, para a destituição do poder familiar, ou destituição de tutela ou guarda. (BRASIL, 1990).
} 
Pelo exposto é possível apontar que o ECA é pautado, sobretudo, no princípio da proteção integral, rompendo com a ultrapassada doutrina da situação irregular trazida pelo antigo Código de Menores. Nesta senda, o legislador elencou as causas que violam ou ameaçam direitos daqueles que não completaram 18 anos, expondo em seguida as consequências para esses atos.

Entre essas consequências, como medida excepcional e provisória, está a medida de acolhimento institucional, que deve ser aplicada somente quando não existir outra medida capaz de afastar a criança ou o adolescente da situação de risco. Para que o acolhimento institucional cumpra o fim a que é destinado, faz-se imprescindível que sejam cumpridos seus princípios, de maneira que haja um atendimento específico para cada criança, adolescente e família, de maneira a atender o caráter transitório da medida, seja para viabilizar a reintegração familiar ou colocação em família substituta (DUPRET, 2010, p. 146).

Desta maneira, apresentado de forma sintética o ECA e sua aplicabilidade de maneira geral, passa-se a abordar nos próximos pontos a questão específica das causas e peculiaridades do acolhimento institucional da criança e do adolescente indígena, após a exposição de um panorama sobre a questão indígena no Brasil, vez que relevante para contextualizar (e atestar) a continuidade do paradigma assimilacionista em algumas práticas estatais, incluindo-se nestas o próprio instituto em comento, mesmo após a promulgação da Constituição de $1988^{6}$.

\section{Contextualizando a temática indígena no estado brasileiro}

Em caráter preliminar, faz-se necessário trazer à tela a questão da definição do que se entende por índio. Assim, cumpre ressaltar, primeiramente, que a denominação "índio" é fruto, em verdade, de uma acepção do colonizador, já que, por conta de um erro marítimo, Cristóvão Colombo, a serviço da Coroa Espanhola, em 1492, não conseguiu chegar às Índias, como pretendia, pisando em terras “novas", porém acreditando tratar-se das Índias, motivo pelo qual, portanto, chamaram os habitantes desse território diverso de "índios" (LUCIANO, 2006, p. 29).

$\mathrm{E}$, antes de demonstrar como os instrumentos normativos positivaram e entendem como critério de determinação do que é "ser índio", salienta-se que, em virtude de toda a diversidade das mais de 300 (IBGE, 2010) comunidades indígenas “(r)existentes” atualmente no Brasil, os conceitos, ainda mais antropológicos, não deveriam primar pela homogeneização

\footnotetext{
6 "Vale evidenciar que, muito embora a inovação da Constituição Federal de 88 no que toca à questão da autodeterminação dos povos, a aceitação e a validação da sua diversidade cultural, além do reconhecimento aos direitos originários das terras, não se vê uma mudança significativa na realidade vivida pelas sociedades indígenas, vez que subordinadas a ações afirmativas e a políticas públicas do Estado, especialmente quanto à demarcação das terras indígenas, para que seus direitos e garantias sejam concretizados" (MONTEIRO; SQUEFF, 2019, p. 137).
} 
(POUTIGNAT; STREIFF-FENART, 2011, p. 159); contudo, tendo em vista o caráter branco, colonialista, eurocêntrico e cristão em que foi erguido o direito brasileiro, é o que se vislumbra nos documentos jurídicos.

Outra questão essencial a ser levantada é a concepção preconceituosa e rasa, despida de um entendimento histórico-cultural, contida nos discursos, principalmente dos 'cidadãos de bem', de que o índio deixa de assim o ser se usar calça jeans ou aparelho celular, se tiver televisão em casa, inclusive se viver em casa e não em "ocas", no meio do mato, até por ser um pensamento um tanto quanto ilógico, uma vez que

[...] se os europeus não permaneceram culturalmente inalterados nesse período, não há razão para pressupor que os índios devam permanecer. Desse fato isolado não se pode concluir que esses povos deixaram de ser indígenas. Os índios, como afirma Mariz Maia, têm consciência de sua continuidade histórica com sociedades précoloniais. Eles não são a reprodução viva dessas sociedades, ou, pelo menos, não precisam ser, para que sejam considerados índios (VITORELLI, 2016, p. 37).

Sendo assim, o conceito de povos tribais e povos indígenas é definido no art. $1^{\mathrm{o}}$ da Convenção de n. 169 da Organização Internacional do Trabalho (OIT), a qual define como povos tribais aqueles cuja condição social, cultural e econômica se distingam de outros setores nacionais e estejam regidos por costumes ou tradições próprios ou legislações especificas e determina como povos indígenas os descendentes de populações que habitavam o país ou região geográfica nacional na época da conquista ou da colonização, ou ainda, do estabelecimento das fronteiras estatais e que mantenham, no todo ou em parte, suas próprias instituições sociais, políticas e econômicas. ${ }^{7}$

Uma problemática acerca dessa definição é apontada por Villares, o qual sustenta que, por conta do caráter universal da legislação internacional, a conceituação acaba por ser não só abrangente, como também categoriza os povos como semelhantes e equiparáveis, de forma que os "povos indígenas, pela Convenção 169 da OIT, são os povos indígenas amazônicos, do sul do Brasil, mas também, os esquimós, os povos do altiplano sul-americano, da América Central e do Norte" (VILLARES, 2013, p. 30).

No Brasil, o conceito de índio, bem como o significado de comunidade indígena ou grupo tribal, é definido no art. $3^{\circ}$ do Estatuto do Índio - Lei Federal n. 6.001 de 19 de dezembro de 1973 -, in verbis:

\footnotetext{
${ }^{7}$ Artigo $1^{\circ} 1$. A presente convenção aplica-se: a) aos povos tribais em países independentes, cujas condições sociais, culturais e econômicas os distingam de outros setores da coletividade nacional, e que estejam regidos, total ou parcialmente, por seus próprios costumes ou tradições ou por legislação especial; b) aos povos em países independentes, considerados indígenas pelo fato de descenderem de populações que habitavam o país ou uma região geográfica pertencente ao país na época da conquista ou da colonização ou do estabelecimento das atuais fronteiras estatais e que, seja qual for sua situação jurídica, conservam todas as suas próprias instituições sociais, econômicas, culturais e políticas, ou parte delas (BRASIL, 2004).
} 
Art. $3^{\circ}$ Para os efeitos de lei ficam estabelecidas as definições a seguir discriminadas: I - Índio ou Silvícola - É todo indivíduo de origem e ascendência pré-colombiana que se identifica e é identificado como pertencente a um grupo étnico cujas características culturais o distinguem da sociedade nacional

II - Comunidade Indígena ou Grupo Tribal - É um conjunto de famílias ou comunidades índias, quer vivendo em estado de completo isolamento em relação aos outros setores da comunhão nacional, quer em contatos intermitentes ou permanentes, sem, contudo, estarem neles integrados.

No sentido do inciso I do artigo, para que haja o reconhecimento do indivíduo como indígena, faz-se necessário que ele cumpra cumulativamente os três requisitos apresentados. Primeiramente, é imprescindível que haja a ascendência pré-colombiana, ou seja, ascendência de antepassados que tenham habitado o território brasileiro antes de sua colonização. A segunda exigência é subjetiva e trata da classificação do indivíduo por ele mesmo e por outros como pertencente a um grupo étnico. Por fim, a exigência de que esse grupo étnico se diferencie da sociedade nacional por suas características culturais (KAYSER, 2010, p. 36).

Pois bem: num texto em que se pretende a criticidade, mostra-se essencial fazer algumas ponderações. O Estatuto do Índio, criado em plena ditatura militar, na década de 1970, em meio a diversas manifestações realizadas pelos movimentos organizados dos povos indígenas, tinha por pretensão garantir, de forma positivada, os direitos. Por se tratar de um instrumento normativo criado por não indígenas para indígenas, a fim e a cabo, reproduz diversas concepções preconceituosas. Um exemplo disso é o próprio art. $1^{\circ}$ da Lei, que afirma ter por objetivo a integração do índio, progressiva e harmoniosamente, à comunhão nacional ${ }^{8}$.

Destrinchando tal dispositivo, nota-se que, em verdade, o que se pretende dizer é que ser índio nada mais é que uma condição transitória, ou seja, que os índios não são tão evoluídos como a sociedade branca, são de um estágio inferior em relação à comunidade nacional, de forma que a incumbência do Estado seria, na visão assimilatória e integracionista, trazer os índios para a sociedade, uma vez que são indivíduos excluídos por ela, no intuito de possibilitar o desenvolvimento destes. É nesse sentido que Vitorelli (2016, p. 34) explica:

\begin{abstract}
Na ótica do princípio integracionista, a cultura nacional deve ser obrigatoriamente homogênea, não devendo coexistir no território brasileiro diferentes organizações sociais, culturais, tradições e línguas, e o meio para alcançar esse ideal é a assimilação "harmoniosa" dos povos indígenas ("minorias menos desenvolvidas") à cultura nacional (sociedade não-índia).
\end{abstract}

Ademais, impende referir que a terminologia escolhida pelo legislador para denominar o índio, como silvícola, também possui traços de um preconceito ainda muito enraizado na

\footnotetext{
8 “[...] [D]e acordo com o próprio artigo $1^{\circ}$ da referida norma, o objetivo principal é a integração dos índios na "comunhão nacional”, ou seja, como explana Ramos (2016, p. 704), 'buscou-se, assim, impor aquilo que era denominado integração harmoniosa dos índios, em um verdadeiro processo de assimilação, pelo qual a condição de índio era transitória', vez que a condição indígena seria algo que até os próprios índios pretenderiam renegar, tornando-se plenamente integrados, afinal se tinha (e ainda se tem) a concepção de que a sociedade ocidental branca é superior, evoluída e mais desenvolvida" (MONTEIRO; SQUEFF, 2019, p. 137).
} 
nossa sociedade colonialista. Isso porque, para além de silvícola determinar que todo índio mora na selva, tal conotação foi usada ao longo dos anos de dominação para caracterizar o índio como o "selvagem", o "bárbaro".

Outrossim, Cunha (2017, p. 109) assevera que hoje, dentro do marco da Constituição de 1988, que avança no sentido de reconhecer a multiculturalidade e a plurietnicidade através dos arts. $215^{9}$ e $231^{10}$, adota-se um critério que define quem são os indígenas a partir de suas organizações sociais, no sentido de que são "populações cujos membros se identificam e são identificados como tais pelos outros, constituindo uma categoria distinta de outras categorias da mesma ordem". Assim, a identidade étnica de um grupo indígena vai se dar essencialmente pela autoidentificação e pela identificação dada pela sociedade envolvente. Ocorre que, como Cunha (2017, p. 110) bem salienta, determinados setores da sociedade "poderão, portanto, ter interesse, em dadas circunstâncias, em negar essa identidade aos grupos indígenas".

Sabe-se que, de acordo com o Censo Demográfico 2010 (IBGE, 2010), existem mais de 900 mil índios no Brasil, representando apenas 0,4\% da população brasileira, sendo o país com a maior diversidade cultural do mundo (FELLET, 2016). Acerca da questão linguística, há dois troncos linguísticos, o Tupi e o Macro-Jê, os quais subdividem-se em famílias linguísticas, que, por sua vez, subdividem-se em línguas (VITORELLI, 2016, p. 50-51). No Brasil, de acordo com o Censo (IBGE, 2010), para crianças de cinco anos ou mais de idade, foram contabilizadas 274 línguas indígenas faladas, sendo a maior diversidade encontrada.

Nesta senda, é possível perceber que a intervenção do Estado, sempre vai merecer muita cautela, porquanto os povos indígenas possuem formas diferentes de viver em comunidade e em família, maneiras diferentes de organização e relacionamento com a natureza, razão pela qual uma intervenção sem prévio conhecimento das diferenças culturais poderá acarretar uma

\footnotetext{
${ }^{9}$ Art. 215. O Estado garantirá a todos o pleno exercício dos direitos culturais e acesso às fontes da cultura nacional, e apoiará e incentivará a valorização e a difusão das manifestações culturais. $§ 1^{\circ} \mathrm{O}$ Estado protegerá as manifestações das culturas populares, indígenas e afrobrasileiras, e das de outros grupos participantes do processo civilizatório nacional. [...]. (BRASIL, 1988).

${ }^{10}$ Art. 231. São reconhecidos aos índios sua organização social, costumes, línguas, crenças e tradições, e os direitos originários sobre as terras que tradicionalmente ocupam, competindo à União demarcá-las, proteger e fazer respeitar todos os seus bens. $\S 1^{\circ}$ São terras tradicionalmente ocupadas pelos índios as por eles habitadas em caráter permanente, as utilizadas para suas atividades produtivas, as imprescindíveis à preservação dos recursos ambientais necessários a seu bem-estar e as necessárias a sua reprodução física e cultural, segundo seus usos, costumes e tradições. $\S 2^{\circ}$ As terras tradicionalmente ocupadas pelos índios destinam-se a sua posse permanente, cabendo-lhes o usufruto exclusivo das riquezas do solo, dos rios e dos lagos nelas existentes. $\S 3^{\circ} \mathrm{O}$ aproveitamento dos recursos hídricos, incluídos os potenciais energéticos, a pesquisa e a lavra das riquezas minerais em terras indígenas só podem ser efetivados com autorização do Congresso Nacional, ouvidas as comunidades afetadas, ficando-lhes assegurada participação nos resultados da lavra, na forma da lei. $\S$ $4^{\circ}$ As terras de que trata este artigo são inalienáveis e indisponíveis, e os direitos sobre elas, imprescritíveis. $\S 5^{\circ}$ É vedada a remoção dos grupos indígenas de suas terras, salvo, "ad referendum" do Congresso Nacional, em caso de catástrofe ou epidemia que ponha em risco sua população, ou no interesse da soberania do País, após deliberação do Congresso Nacional, garantido, em qualquer hipótese, o retorno imediato logo que cesse o risco. $\S 6^{\circ}$ São nulos e extintos, não produzindo efeitos jurídicos, os atos que tenham por objeto a ocupação, o domínio e a posse das terras a que se refere este artigo, ou a exploração das riquezas naturais do solo, dos rios e dos lagos nelas existentes, ressalvado relevante interesse público da União, segundo o que dispuser lei complementar, não gerando a nulidade e a extinção direito a indenização ou a ações contra a União, salvo, na forma da lei, quanto às benfeitorias derivadas da ocupação de boa fé. $\S 7^{\circ} \mathrm{Não}$ se aplica às terras indígenas o disposto no art. 174, $\S 3^{\circ}$ e $\S 4^{\circ}$. (BRASIL, 1988).
} 
dupla vitimização das crianças ou adolescentes que se pretende proteger, conforme será analisado no tópico a seguir.

\section{0 acolhimento institucional de crianças e adolescentes indígenas: apontamentos e desafios}

Historicamente, o acolhimento institucional de crianças indígenas teve início no período colonial, com a chegada dos primeiros europeus. Nesse período, marcado por aprisionamento e domesticação de indígenas, os padres jesuítas criaram estratégias para facilitar o acesso às riquezas nacionais e à mão-de-obra abundante. Entre essas estratégias estava o controle sobre os pequenos índios. Desse modo, com o propósito de catequizá-los e acabar com sua identidade indígena, as crianças eram criadas longe de suas famílias e expostas a severos castigos físicos em caso de desobediência. Assim, segundo Fachinetto (2009, p. 21-22), "[p]elas mãos dos jesuítas surgiram, neste momento, as primeiras instituições destinadas às crianças no Brasill”.

Por tais exposições é que se verifica que, de fato, o Brasil não desenvolveu uma política social realmente adequada aos anseios e necessidades dos povos indígenas. Pelo contrário, a lógica que se deu foi de primeiramente expulsão, confinamento e exclusão, partindo, posteriormente, para uma dialética de vínculo com o Estado, a partir da política assistencialista.

A Constituição Federal de 1988 rompeu com o paradigma integracionista e de aculturação até então vigente, reconhecendo aos povos, em virtude de conceber o país como pluriétnico e com vasta diversidade cultural, o direito à diferença, garantindo-se, portanto, a cada grupo o livre desenvolvimento a partir de suas tradições, costumes, visões de mundo e, principalmente, assegurando o seu direito originário às terras (art. 231, supracitado). Outra inovação da Constituição Federal de 1988 foi o seu art. 232 ${ }^{11}$, que trata do reconhecimento da capacidade processual indígena, de suas comunidades e organizações para defender os interesses, conferindo ao Ministério Público o dever de garantir esses direitos e intervir nos processos em que estejam em pauta direitos e interesses indígenas (ARAÚJO, 2008, p. 217 256).

Entretanto, quanto à proteção de crianças e adolescentes indígenas, o ECA, em seu texto original de 1990, não fazia nenhuma referência específica. A aplicação das normas constantes no ECA às crianças e aos jovens indígenas somente teve regulamentação na Resolução do Conselho Nacional dos Direitos da Criança e do Adolescente - Conanda - de número 91, datada

\footnotetext{
${ }^{11}$ Art. 232. Os índios, suas comunidades e organizações são partes legítimas para ingressar em juízo em defesa de seus direitos e interesses, intervindo o Ministério Público em todos os atos do processo. (BRASIL, 1988).
} 
de 23 de junho de 2003. ${ }^{12}$ De acordo com o documento, as disposições do ECA são aplicáveis às crianças e aos adolescentes indígenas, contanto que sejam observadas as suas peculiaridades e características particulares.

Ademais, especificamente quanto ao acolhimento institucional de crianças e adolescentes indígenas, não há menção no ECA; todavia, uma das alterações promovidas pela Lei Federal n. 12.010 de 2009 incorpora ao art. 28, do ECA, que trata da colocação em família substituta, o $\S 6^{\circ}$, I, II e III ${ }^{13}$, dispondo que, para ocorrer a colocação de indígena em família substituta, é necessário que a inserção aconteça com respeito aos seus costumes e tradição, que sua colocação seja realizada, preferivelmente, junto à sua comunidade ou membros da mesma etnia e que haja intervenção e oitiva de representantes do órgão federal responsável pela política indigenista (ROSSATO, 2012, p. 183). Acerca do tema, explica Barros (2010, p. 65):

Mais uma inovação trazida pela Lei $\mathrm{n}^{\circ} 12.010 / 2009$ se refere à previsão de
observância das peculiaridades dos jovens indígenas ou provenientes de comunidade
remanescente de quilombo. De acordo com o parágrafo $6^{\circ}$, a identidade social e
cultural do menor deve ser sopesada. Para isso, a preferência legal é pela colocação
da criança ou adolescente em família substituta da mesma comunidade ou grupo
étnico. Por fim, estabelece-se a necessidade de participação de representantes dos
órgãos federais de política indigenista e antropólogos no caso de quilombolas.

Tal entendimento é fundamental em um contexto em que se busca a promoção da diversidade cultural e o respeito às diferenças. Além do mais, é importante observar que embora o dispositivo esteja localizado na parte que trata da colocação em família substituta, ele se aplica igualmente aos casos de acolhimento institucional como forma de abreviar a situação de acolhimento daquela criança ou adolescente indígena, tendo em vista que o acolhimento institucional tem como consequência a reinserção familiar ou a colocação em família substituta. Assim, é imperioso que desde o princípio da intervenção haja a comunicação com a instituição indigenista, porquanto é ela que, por meio de seus assistentes sociais, busca a melhor solução junto à aldeia de onde a criança ou adolescente foi retirado (SANTOS, 2014).

Assim, é possível afirmar que, de acordo com o inciso III do $\S 6^{\circ}$ do art. 28 do ECA ${ }^{14}$, a intervenção da Fundação Nacional do Índio - FUNAI (órgão indigenista oficial do Estado

\footnotetext{
${ }^{12}$ Art. $1^{\circ}$ Firmar o entendimento esposado pela Assembleia Ordinária do CONANDA, realizada nos dias 14 e 15 de maio de 2003 , no sentido de que se aplicam à família, à comunidade, à sociedade, e especialmente à criança e ao adolescente indígenas as disposições constantes da Lei $\mathrm{n}^{\circ}$ 8.069, de 13 de julho de 1990, que dispõe sobre o Estatuto da Criança e do Adolescente, observadas as peculiaridades sócio-culturais das comunidades indígenas. (CONANDA, 2003).

13 Art. 28, § 60 Em se tratando de criança ou adolescente indígena ou proveniente de comunidade remanescente de quilombo, é ainda obrigatório: I - que sejam consideradas e respeitadas sua identidade social e cultural, os seus costumes e tradições, bem como suas instituições, desde que não sejam incompatíveis com os direitos fundamentais reconhecidos por esta Lei e pela Constituição Federal; II - que a colocação familiar ocorra prioritariamente no seio de sua comunidade ou junto a membros da mesma etnia; III - a intervenção e oitiva de representantes do órgão federal responsável pela política indigenista, no caso de crianças e adolescentes indígenas, e de antropólogos, perante a equipe interprofissional ou multidisciplinar que irá acompanhar o caso. (BRASIL, 1990).

${ }^{14}$ Art. 28, §6º, inc. III - a intervenção e oitiva de representantes do órgão federal responsável pela política indigenista, no caso de crianças e adolescentes indígenas, e de antropólogos, perante a equipe interprofissional ou multidisciplinar que irá acompanhar o caso. (BRASIL, 1990).
} 
brasileiro responsável pela proteção e promoção dos direitos dos povos indígenas) nas ações que envolvam crianças ou jovens indígenas é obrigatória, já que possibilita a atuação ativa do órgão na fiscalização de processos, garantindo o respeito aos direitos fundamentais, bem como apontando as especificidades a serem atendidas antes do deferimento de guarda, tutela ou adoção da criança ou adolescente indígena (SANTOS, 2014).

É importante salientar que a Constituição Federal de 1988 criou diversos órgãos com atuação vinculada aos povos indígenas, em vários ministérios, ampliando a relação entre estes e o Estado. Como exemplo, os casos da saúde indígena passaram a ser responsabilidade do Ministério da Saúde, especificamente da Fundação Nacional de Saúde (FUNASA), que atua na inclusão dos povos indígenas em programa de prevenção e controle de doenças (LUCIANO, 2006, p. 73), assim como a Secretaria Especial da Saúde indígena (SESAI), que atua na atenção à saúde indígena no âmbito do Sistema Único de Saúde (SUS) (MINISTÉRIO DA SAÚDE, [s.d.]). Nesse sentido, a FUNAI não pode ser considerada o órgão indigenista absoluto, em que pese a sua importância e atribuições legalmente instituídas (LUCIANO, 2006, p. 73).

O modo de intervenção da FUNAI nos casos em que haja violação de direitos de crianças e jovens indígenas foi regulado pela Instrução Normativa n. 01, de setembro de 2014, que trouxe importantes esclarecimentos quanto à interferência do órgão. A referida instrução conceitua, no parágrafo único do art. $1^{\mathrm{o15}}$, a situação de risco quando crianças e jovens indígenas se encontrarem em circunstâncias de iminente ou consumado afastamento do convívio familiar e comunitário, ou que estejam sofrendo violação aos direitos previstos no art. 227 da atual Constituição brasileira.

Ademais, nos casos em que houver a necessidade de acolhimento provisório de crianças e jovens indígenas, a mencionada Instrução Normativa descreve a ordem de procedimentos a serem adotados pelos órgãos locais, definindo prioridade de inserção imediata na família nuclear ou extensa, deliberando sobre a atuação dos Conselhos Tutelares locais e a necessidade de envio de relatórios contendo dados relevantes da criança ou adolescente acolhido (FUNAI, 2014).

Neste diapasão, destaca-se que o Conselho Tutelar, previsto no art. 131 do $\mathrm{ECA}^{16}$, é órgão fundamental no sistema de acolhimento institucional de crianças e adolescentes indígenas, vez que possui, entre outras, as atribuições de atender crianças e adolescentes cujos direitos estejam sendo ameaçados ou violados, aplicar medidas de proteção e realizar os

\footnotetext{
${ }^{15}$ Art. $1^{\text {a }}$, parágrafo único. Consideram-se em situação de risco as crianças e jovens indígenas que se encontram em situação de eminente ou consumado afastamento do convívio familiar ou comunitário, ou que estejam sofrendo violações aos direitos previstos no artigo 227 da Constituição Federal (FUNAI, 2014).

${ }^{16}$ Art. 131. O Conselho Tutelar é órgão permanente e autônomo, não jurisdicional, encarregado pela sociedade de zelar pelo cumprimento dos direitos da criança e do adolescente, definidos nesta Lei. (BRASIL, 1990).
} 
encaminhamentos ao Ministério Público e à Autoridade Judiciária em casos de violação de direitos. No que se refere a crianças e adolescentes indígenas, os conselheiros tutelares encontram desafios, pois trata-se de um contexto específico, que demanda maior conhecimento e capacitação para entendimento das culturas distintas (ASSIS; FARIAS, 2013).

Para a constatação da situação de risco e vulnerabilidades é fundamental o papel da rede de proteção, mais especificamente, nos casos envolvendo indígenas, o Conselho Tutelar e o Centro de Referência de Atendimento Social (CRAS), já que são eles que prestam os atendimentos diretamente à família em suas demandas sociais. Nesse sentido, considerando as peculiaridades atinentes aos povos indígenas, foi elaborado pelo Ministério do Desenvolvimento Social (MDS) (2017) o documento “Trabalho Social Com Famílias Indígenas na Proteção Social Básica", que auxilia nos procedimentos teóricos e práticos das equipes de assistência social que atendem famílias e comunidades indígenas, visando à convivência familiar e comunitária e ao acesso de direitos.

De acordo com o documento (MDS, 2017, p. 41), o trabalho social com famílias indígenas deve ter como base a observação cuidadosa da realidade local e respeito às diferenças asseguradas aos povos indígenas. Sugere-se que inicialmente se tenha o contato com os líderes da comunidade (Caciques, anciãos, Conselheiros), os novos líderes (professores e diretores de escola indígena, presidentes de associação comunitária) e ainda, com a articulação que atue no território, garantindo assim que o trabalho social alcance as famílias mais vulneráveis.

Diante das legislações e conceitos apresentados, é possível obter uma compreensão das diferenças quando se trata da proteção da criança e do adolescente indígena em comparação aos não-indígenas. Além de toda intervenção ser pautada no respeito aos costumes e tradições, fazse obrigatória a intervenção do órgão indigenista desde a identificação da situação de risco, passando pelos casos de acolhimento institucional e, quando for o caso, a colocação da criança ou adolescente em família substituta.

Nota-se que, mesmo com o implemento das especificidades do ECA referentes às crianças e aos adolescentes indígenas, bem como com os direitos dispostos na Constituição de 1988, ainda é possível verificar uma constante violação de direitos desses povos em situações de vulnerabilidades, uma vez que, quando ocorre a intervenção do Estado na proteção de indígenas, na maioria das vezes não há um conhecimento da cultura daquela criança ou adolescente que se pretende proteger, razão pela qual ao serem acolhidos institucionalmente, acabam sendo mantidos em entidades de acolhimento que diferem das suas comunidades em diversos aspectos, tornando mais difícil o seu retorno à família de origem. 
No intuito de demonstrar a violação aos direitos elencados no $\S 6^{\circ}$ do art. 28 do ECA serão debatidas duas decisões. A primeira, uma decisão do Superior Tribunal de Justiça (STJ) que trata da validade da colocação de indígena acolhido institucionalmente e inscrito no Cadastro Nacional de Adoção em família substituta comum, inexistindo a intervenção do órgão indigenista no processo (STJ, 2017). Nesse caso, a criança encontrava-se inserida na família substituta há quatro anos. O acórdão do referido caso está assim ementado:

RECURSO ESPECIAL. CONSTITUCIONAL. CIVIL. DIREITO INDÍGENA. COLOCAÇÃO DE MENOR INDÍGENA EM FAMÍLIA SUBSTITUTA. PREVISÃO DE INTERVENÇÃO OBRIGATÓRIA DA FUNAI NO PROCESSO. NECESSIDADE DE DEMONSTRAÇÃO DO PREJUÍZO PARA QUE A NULIDADE SEJA DECRETADA. NÃO OCORRÊNCIA NO CASO DOS AUTOS. CRIANÇA INSERIDA HÁ QUATRO ANOS EM FAMÍLIA COMUM. CONSTITUIÇÃO DE LAÇOS AFETIVOS. RECURSO IMPROVIDO. 1. No inciso III do $\S 6^{\circ}$ do art. 28 da Lei 8.069/1990 (ECA), introduzido pela Lei 12.010/2009 (Lei Nacional da Adoção), está disciplinada a obrigatoriedade de participação do órgão federal de proteção ao indígena, a Fundação Nacional do Índio - FUNAI -, além de antropólogos, em todos os procedimentos que versem sobre a colocação do menor indígena em família substituta, seja por meio de guarda, tutela ou adoção. 2. A intervenção da FUNAI nesses tipos de processos é de extrema relevância, porquanto os povos indígenas possuem identidade social e cultural, costumes e tradições diferenciados, tendo, inclusive, um conceito de família mais amplo do que o conhecido pela sociedade comum, de maneira que o ideal é a manutenção do menor indígena em sua própria comunidade ou junto a membros da mesma etnia. A atuação do órgão indigenista visa justamente a garantir a proteção da criança e do jovem índio e de seu direito à cultura e à manutenção da convivência familiar, comunitária e étnica, tendo em vista que a colocação do menor indígena em família substituta não indígena deve ser considerada a última medida a ser adotada pelo Estado. 3. A adoção de crianças indígenas por membros de sua própria comunidade ou etnia é prioritária e recomendável, visando à proteção de sua identidade social e cultural. Contudo, não se pode excluir a adoção fora desse contexto, pois o direito fundamental de pertencer a uma família sobrepõe-se ao de preservar a cultura, de maneira que, se a criança não conseguir colocação em família indígena, é inconcebível mantê-la em uma unidade de abrigo até sua maioridade, sobretudo existindo pessoas não indígenas interessadas em sua adoção. 4. A ausência de intervenção obrigatória da FUNAI no processo de colocação de menor indígena em família substituta é causa de nulidade. A decretação de tal nulidade, contudo, deve ser avaliada em cada caso concreto, pois se, a despeito da não participação da FUNAI no processo, a adoção, a guarda ou tutela do menor indígena envolver tentativas anteriores de colocação em sua comunidade ou não for comprovado nenhum prejuízo ao menor, mas, ao contrário, forem atendidos seus interesses, não será recomendável decretar-se a nulidade do processo. 5. No caso concreto, verificou-se que: (I) tal como a FUNAI em seu agravo de instrumento, o ora recorrente, representado pela curadoria especial, agora no recurso especial não indicou concretamente qual seria o prejuízo que teria o menor indígena ou seu genitor sofrido com o encaminhamento à instituição de acolhimento e a inscrição no Cadastro Nacional de Adoção (CNA); (II) não foi interposto recurso especial particularmente pela FUNAI, o que leva à conclusão que tenha o órgão indigenista se conformado com o acórdão proferido pelo Tribunal estadual e entendido por bem deixá-lo transitar em julgado; (III) na prática, conforme salientado pelas instâncias ordinárias, apesar da não intervenção do órgão indigenista no feito, foram realizadas diversas tentativas para que o acolhimento das crianças fosse efetivado por seus famílias indígenas. Somente quando se mostraram infrutíferas as diligências é que se deu prosseguimento ao pedido de destituição do poder familiar, de adoção e de inscrição no CNA. Portanto, não está demonstrado, na hipótese dos autos, nenhum prejuízo aos menores indígenas, de maneira que não se mostra recomendável a decretação da nulidade do 
processo por ausência de intervenção da FUNAI. 6. A criança indígena adotada foi inserida em família comum com cinco anos de idade, em 15/02/2013, há mais de quatro anos, portanto, a indicar que o decreto de nulidade, na hipótese, seria prejudicial aos próprios interesses do menor, uma vez já consolidados os vínculos de afetividade, os quais seriam desfeitos em prestígio de formalidade. 7. Recurso especial improvido. (BRASIL. Superior tribunal de Justiça. REsp n. 1566808/MS 2015/0288539-3, Relator: Ministro Marco Aurélio Bellizze, Data de Julgamento: 19/09/2017, Terceira Turma. Data da publicação: Dje 02/10/2017) (grifou-se).

Analisando a decisão supra, observa-se que o Ministro Marco Aurélio Bellizze reconhece a obrigatoriedade de participação da FUNAI e de antropólogos nas intervenções envolvendo crianças indígenas, sendo essa intervenção de extrema relevância, tendo em vista que é o órgão indigenista que visa a garantir o direito à cultura e à manutenção do convívio familiar. Destaca ainda que a ausência de participação do órgão seria caso de nulidade, porém afirma que não é recomendada a decretação da nulidade nos casos em que forem atendidos os interesses da criança.

Em suas razões, o Ministro refere que, apesar da não participação do órgão indigenista, não restaram demonstrados os prejuízos concretos para o indígena no caso em apreço, visto que foram realizadas tentativas para sua reinserção na família de origem, assim como o decurso de tempo em que a criança indígena restou junto à família substituta -mais de quatro anos - faz com que a decretação da nulidade seja prejudicial caso atendida, pois já ter-se-ia consolidado o vínculo, de modo que configurar-se-ia em uma afronta aos interesses da criança.

Todavia, apesar de convincente, entende-se que a ratio decidendi do ilustre Ministro não poderia ter seguido essa linha à luz da preservação da cultura indígena, bem como à luz da pluralidade brasileira, reconhecida na Constituição de 1988, anteriormente referida. Sabe-se que a criança já estava inserida no seio da família substituta "comum" há um tempo deveras significativo; todavia, questiona-se como ele, um membro do Poder Judiciário, poderia compreender o que seria do melhor interesse para o indígena consoante a sua cultura? Para tanto a FUNAI (órgão do Poder Executivo) deveria ter sido consultada - certamente em um tempo menor -, e não o Poder Judiciário na pessoa do Ministro do STJ, fora de suas capacidades, em atenção à separação dos poderes.

Essa lógica também foi repisada em uma decisão do Tribunal de Justiça do Estado de Mato Grosso do Sul (TJMS) (2014) que julgou um agravo de instrumento interposto por uma indígena, Sinforiana, contra decisão que deferiu a guarda provisória de suas filhas acolhidas institucionalmente, Mareilen e Sara, a um casal não indígena, porém, habilitado e no topo da lista de adoção. Esse recurso teve como fundamento o desrespeito ao artigo $28, \S 6^{\circ}$, do ECA, 
visto que a guarda das crianças indígenas foi deferida a família não indígena sem a oitiva da FUNAI e da realização de laudo antropológico. A ementa deste acórdão está assim disposta:

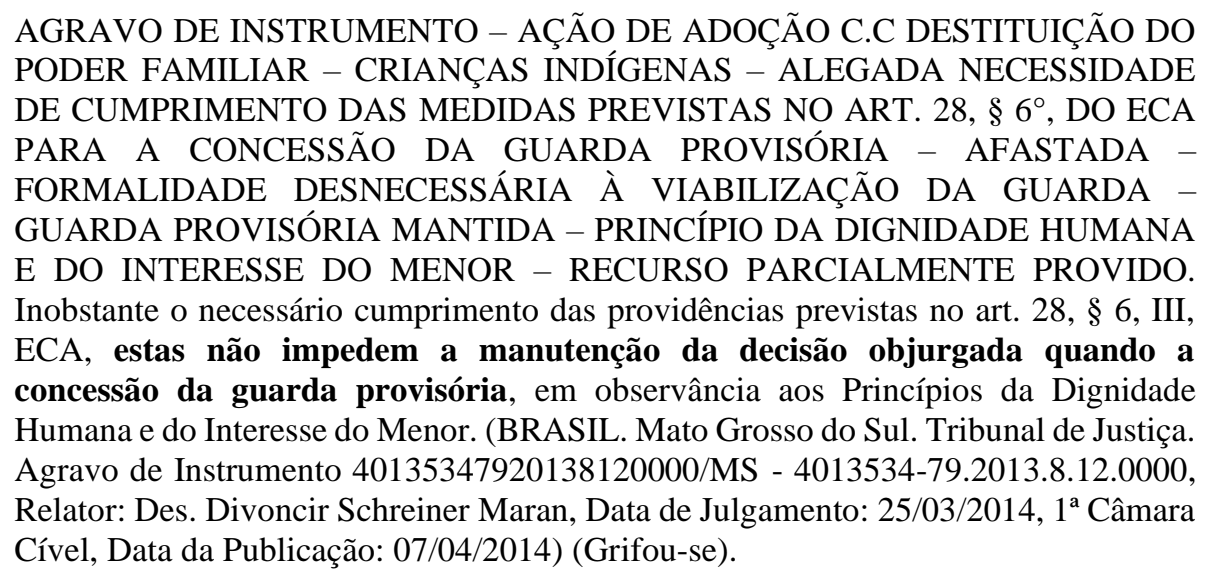

Na decisão, o Desembargador Relator do TJMS, Divoncir Schreiner Maran, reconhece o necessário cumprimento das providências elencadas no artigo $28, \S 6^{\circ}$ do ECA; porém, afirma que a concessão da guarda provisória deveria ser mantida em observância aos princípios da Dignidade Humana e do Superior Interesse da Criança, ambos ressaltados anteriormente no presente ensaio. Em suas razões, o Relator expôs que, "mais do que atentar para as formalidades previstas no art. $28, \S 6^{\circ}$, III, do ECA, para a viabilização da guarda provisória, cumpre focalizar o interesse das infantes, devendo este sempre prevalecer acima dos demais" (TJMS, 2014, p. 3).

Logo, seguindo a ratio do magistrado, o recurso foi parcialmente provido para manter a guarda provisória das crianças indígenas na família substituta comum, a fim de que, então, fosse realizada a oitiva da FUNAI e consequente laudo antropológico. Todavia, novamente, nota-se que essa conduta viria a frustrar os próprios princípios constitucionais atinentes ao respeito da pluralidade étnico-cultural brasileira, particularmente por se tratar de guarda provisória, o que provavelmente prejudicaria a sustentação da cultura das crianças, sua identidade enquanto indígenas, além da perda dos costumes próprios de sua comunidade, os quais são repassados a partir do convívio e da oralidade.

A relativização da obrigatoriedade de intervenção do órgão indigenista antes do deferimento da guarda pelo magistrado do Egrégio TJMS em prol da família substituta, em nome de um "suposto" superior interesse do indígena, não deveria ter ocorrido. Esse princípio, elencado no art. 3(1) da Convenção dos Direitos das Crianças de $1989^{17}$, bem como no art. 100,

\footnotetext{
${ }^{17}$ Art. 3(1). Todas as ações relativas às crianças, levadas a efeito por instituições públicas ou privadas de bem-estar social, tribunais, autoridades administrativas ou órgãos legislativos, devem considerar, primordialmente, o interesse maior da criança. (BRASIL, 1946).
} 
IV do ECA $^{18}$, segundo Nucci $(2015$, p. 314), garante que os direitos infanto-juvenis sejam colocados acima de outros direitos que possam entrar em conflito. Contudo, aqui o que estaria em conflito seria a própria preservação das raízes da criança ou adolescente em relação à sua comunidade indígena e a sua inserção em um ambiente "comum", que levaria a uma perda de sua identidade enquanto indígena, cuja análise não deveria ser realizada por um representante do Poder Judiciário, senão, no mínimo, pela FUNAI, em atenção à separação de poderes.

Por mais que nos dois casos apresentados a revogação da guarda não trouxesse benefícios "visíveis" aos infantes ao olho do "homem branco", visto que os vínculos já estavam consolidados e as crianças protegidas no seio de uma família comum, é importante lembrar que a interpretação principiológica deveria levar em consideração a pluralidade étnico-cultural do Estado brasileiro. Logo, mesmo que essas características sejam importantíssimas (senão de cumprimento obrigatório) em um caso de acolhimento de uma criança ou adolescente "branco", ela não poderia ser "facilmente" expandida para o caso do acolhimento de indígena.

Por esta razão é que a participação da FUNAI desde o início da intervenção estatal é necessária a fim de resguardar os interesses do indígena. Afinal, é este órgão quem possui a competência para efetivar medidas que viabilizam o retorno dessa criança ou adolescente à família natural, tendo o dever legal de conhecimento a respeito das diversidades culturais desses povos e suas especificidades - e não o Poder Judiciário, na pessoa dos magistrados e ministros, em sua maioria homens brancos ocidentais de alto poder aquisitivo, julgando a partir de sua própria consciência e cultura.

Assim, verifica-se que, no que toca às questões indígenas, em que pese o caráter progressista do texto constitucional, no sentido de reconhecer a autodeterminação dos povos e aceitar e a validar a sua diversidade cultural, não se observa faticamente uma mudança significativa na realidade vivida pelas sociedades indígenas, vez ainda sofrerem com os preconceitos colonialistas estruturados na sociedade brasileira, além de resistirem a um sistema jurídico que as desqualifica e ignora enquanto indígenas, desrespeitando suas particularidades e depreciando sua cultura e identidade, já que houve uma imposição do modelo ocidental de criação e cumprimento das leis.

Portanto, na visão de Dornelles, Brum e Veronese (2017, p. 39), para que os direitos dos povos indígenas sejam efetivados é fundamental uma harmonização intercultural que propicie o diálogo entre os povos indígenas e a sociedade nacional. Os autores sustentam que "é por

\footnotetext{
${ }^{18}$ Art. 100. Na aplicação das medidas levar-se-ão em conta as necessidades pedagógicas, preferindo-se aquelas que visem ao fortalecimento dos vínculos familiares e comunitários. [...] IV - interesse superior da criança e do adolescente: a intervenção deve atender prioritariamente aos interesses e direitos da criança e do adolescente, sem prejuízo da consideração que for devida a outros interesses legítimos no âmbito da pluralidade dos interesses presentes no caso concreto. (BRASIL, 1990).
} 
meio da promoção de um diálogo intercultural e da preocupação em considerar o entendimento da cultura indígena que se tornará possível observar em que pontos as culturas poderão se flexibilizar para que o entendimento seja alcançado e, assim, ações conjuntas possam ser desenvolvidas".

\section{Considerações finais}

Partindo do pressuposto de que o acolhimento institucional é um instituto bastante importante para evitar a contínua violação de direitos de crianças e adolescentes em seus lares; porém, que para que uma criança ou adolescente seja excepcionalmente conduzida a um lar substitutivo, deveriam ser considerados diversos aspectos, dentre os quais a própria manutenção das tradições e costumes para o seu contínuo desenvolvimento, o presente texto tinha como objetivo analisar de forma sistemática e crítica de se, nos casos particulares de necessário acolhimento institucional de crianças e adolescentes indígenas, as leis pátrias referentes ao respeito à cultura desses povos estão sendo respeitadas.

E para que fosse possível chegar à conclusão de que as normas que versam sobre direitos culturais são violadas nos casos de acolhimento de crianças e adolescentes indígenas, foi necessário tecer uma linha de raciocino que permitisse compreender os princípios da medida de proteção e acolhimento institucional aplicável às crianças e adolescentes de forma geral, analisar o caso específico de acolhimento institucional de crianças e adolescentes indígenas e as legislações pertinentes ao tema, bem como as situações que levam as crianças e adolescentes à exposição a riscos, observando, então, a intervenção e a visão das equipes de atendimento quanto à família indígena.

Com efeito, nos casos em que há a necessidade de intervenção do Estado, este deveria, em conformidade com as leis internas e internacionais devidamente ratificadas pelo Brasil, disponibilizar locais de atendimento que sustentassem a continuidade da cultura dos indígenas, bem como garantissem que políticas públicas efetivas fossem aplicadas nas aldeias com intuito de evitar que as retiradas de crianças e jovens de suas comunidades fossem necessárias e promover condições para que as famílias pudessem se organizar de maneira a receber de volta os que por ventura fossem institucionalizados.

Outrossim, notou-se que a intervenção do órgão indigenista - FUNAI - deveria ser respeitada integralmente pelo Poder Judiciário e equipes de atendimento da rede de proteção, sem que fosse considerada uma mera formalidade, pois é sua obrigação não só fazer respeitar os costumes e a própria cultura indígena, como também garantir que as tentativas de reinserção na comunidade de origem sejam realmente efetuadas. Dessa forma, não poderia o Poder 
Judiciário, por intermédio de seus ministros, desembargadores e juízes, julgar questões que envolvam a preservação cultural pautados no princípio do melhor interesse da criança e adolescente, eis que, ao fazê-lo, contradizem toda a legislação interna e internacional específica, as quais garantem o respeito à pluralidade étnico-cultural - inclusive a própria Carta de 1988.

Sendo assim, percebeu-se que não faltam normas garantindo o reconhecimento e respeito a esses direitos; na verdade, o que falta é a sua plena observância, posto que a sua ponderação - como observada nos casos debatidos do STJ e do TJMS - não atendeu plenamente aos interesses tanto das crianças indígenas (à luz de sua cultura) quanto nacionais (referentes ao Estado plurinacional). Desta feita, conclui-se que, para que os direitos garantidos aos povos indígenas sejam realmente postos em prática, faz-se necessário um diálogo constante entre a sociedade não-indígena e as comunidades indígenas, propiciando um maior entendimento quando à suas demandas para se chegar a soluções que possam efetivamente superar os conflitos históricos e acabem com os preconceitos e estigmas dispensados aos povos indígenas no Brasil, reconhecendo, sobretudo, o seu direito à diferença.

\section{Referências}

ARAÚJO, Ana Valéria. Povos indígenas e igualdade Étnico-Racial. In: PIOVESAN, Flavia; SOUZA, Douglas de. (Coord.). Ordem jurídica e igualdade étnico racial. Rio de Janeiro: Lumen Juris, 2008.

ASSIS, Simone Gonçalves de; FARIAS, Luís Otávio Pires (org.) Levantamento Nacional das Crianças e Adolescentes em Serviços de Acolhimento. São Paulo: HUCITEC, 2013. Disponível em: <https://goo.gl/3tmmF5>. Acesso em: 11 out. 2017.

BARROS, Guilherme Freire de Melo Barros. Estatuto da Criança e do Adolescente: Lei ${ }^{\circ}$ 8.069/1990. 3. ed. Bahia: Juspodivm, 2010.

BRASIL. Decreto n. 5.051 de 19 de abril de 2004. Planalto. Disponível em: <https://goo.gl/hfiMNk>. Acesso em: 29 out. 2017.

BRASIL. Decreto n. 99.710 de 03 de setembro de 1946. Planalto. Disponível em: <https://goo.gl/K2K18P>. Acesso em: 28 de out. 2017.

BRASIL. Lei n. 6.001, de 19 de dezembro de 1973. Planalto. Disponível em: <https://goo.gl/iGH4kJ>. Acesso em: 08 nov. 2017.

BRASIL. Lei n. 8.069, de 13 de julho de 1990. Planalto. Disponível em: <https://goo.gl/yZrq4a>. Acesso em: 08 set. 2017.

CARNEIRO, Rosa Maria Xavier Gomes (coord.). Curso de Direito da Criança e do Adolescente: Aspectos Teóricos e Práticos. 4. ed. Rio de Janeiro: Lumen Juris, 2010. 
CONANDA - CONSELHO NACIONAL DO DOS DIREITOS DA CRIANÇA E DO ADOLESCENTE. Resolução n. 91, de 23 de junho de 2003. Disponível em: <https://goo.gl/emtynC>. Acesso em: 11 out. 2017.

CNMP - CONSELHO NACIONAL DO MINISTÉRIO PÚBLICO. CNMP divulga dados sobre acolhimento de crianças e adolescentes. Brasília, 8 ago. 2013. Disponível em: $<$ https://www.cnmp.mp.br/portal/todas-as-noticias/3702-cnmp-divulga-dados-sobreacolhimento-de-criancas-e-adolescentes >. Acesso em: 20 abr. 2020.

CNMP - CONSELHO NACIONAL DO MINISTÉRIO PÚBLICO. Relatório traz dados sobre acolhimento e internação de jovens. Brasília, 2 fev. 2016. Disponível em: $<$ https://www.cnmp.mp.br/portal/todas-as-noticias/8963-relatorio-traz-dados-sobreacolhimento-e-internacao-de-jovens>. Acesso em: 20 abr. 2020.

CUNHA, Manuela Carneiro da. Índios no Brasil: história, direitos e cidadania. São Paulo: Claro Enigma, 2017.

CURY, Munir (coord.). Estatuto da Criança e do Adolescente Comentado: Comentários jurídicos e sociais. 11. ed. São Paulo: Malheiros, 2010.

DORNELLES, Ederson Nadir Pires; BRUM, Fabiano Prado de; VERONESE, Osmar. Indígenas no Brasil: (in)Visibilidade social e jurídica. Curitiba: Juruá, 2017.

DUPRET, Cristiane. Curso de Direito da Criança e do Adolescente. Belo Horizonte: IUS, 2010 .

FACHINETTO, Neidemar José. O direito à convivência familiar e comunitária: contextualizando com as políticas públicas (in)nexistentes. Porto Alegre: Livraria do Advogado, 2009.

FELLET, João. 305 etnias e 274 línguas: estudo revela riqueza cultural entre índios no Brasil. BBC Brasil. Notícia veiculada em 3 jul. 2016. Disponível em: <www.bbc.com/portuguese/brasil-36682290>. Acesso em 02.11. 2017.

FONSECA, Patrícia Nunes da. O impacto do acolhimento institucional na vida de adolescentes. Revista Psicopedagogia, São Paulo, v. 34, n. 105, pp. 285-296, 2017.

FUNAI - FUNDAÇÃO NACIONAL DO ÍNDIO. Instrução Normativa n. 01, de 22 de setembro de 2014. Disponível em: 〈https://goo.gl/URfo3A〉. Acesso em: 12 out. 2017. IBGE. Características Gerais dos Indígenas - Resultados do Universo. Censo Demográfico 2010. Rio de Janeiro: IBGE, 2010. Disponível em:

<https://biblioteca.ibge.gov.br/visualizacao/periodicos/95/cd_2010_indigenas_universo.pdf> Acesso em 07.10.2017.

ISHIDA, Valter Kenji, Estatuto da Criança e do Adolescente: doutrina e jurisprudência. 11. ed. São Paulo: Atlas, 2010.

KAYSER, Hartmut-Emanuel. Os direitos dos povos indígenas do Brasil: desenvolvimento histórico e estágio atual. Trad. Maria da Glória Lacerda, Klaus-Peter Rurack. Porto Alegre: Sergio Antonio Fabris, 2010. 
LUCIANO, Gersem dos Santos. O Índio Brasileiro: o que você precisa saber sobre os povos indígenas no Brasil de hoje. Coleção Educação para Todos. Brasília: Ministério da Educação, 2006.

MINISTÉRIO DA SAÚDE. Secretaria Especial da Saúde Indígena (SESAI). Brasília, [s.d.] Disponível em: 〈https://goo.gl/RTY6A3>. Acesso em 08 nov. 2017.

MDS - MINISTÉRIO DO DESENVOLVIMENTO E SOCIAL. Trabalho social com famílias indígenas na proteção social básica. Brasília, DF: MDS, Secretária Nacional de Assistência Social, 2017.

MONTEIRO, Michelle Alves; SQUEFF, Tatiana Cardoso. Brasil, um país de todos? A questão territorial indígena no Ordenamento Jurídico Brasileiro e a construção de um Estado Plurinacional. Revista Culturas Jurídicas, Rio de Janeiro, v. 6, n. 13, pp. 117-144, jan./abr., 2019

NUCCI, Guilherme de Souza. Estatuto da Criança e do Adolescente Comentado: em busca da Constituição Federal das crianças e dos adolescentes. 2. ed. rev., atual. Rio de Janeiro: Forense, 2015.

POUTIGNAT, Philippe; STREIFF-FENART, Jocelyne. Teorias da Etnicidade: seguido de Grupos Étnicos e suas Fronteiras de BARTH, Fredrik. 2.ed. São Paulo: Unesp, 2011.

RAMOS, André de Carvalho. Curso de Direitos Humanos. 3. Ed. rev. atual. ampl. São Paulo: Editora Saraiva, 2016.

ROSSATO, Luciano Alves. Estatuto da Criança e do Adolescente Comentado: Lei 8,069/1990: artigo por artigo. 4. ed. rev. atual. e ampl. São Paulo: Revista dos Tribunais, 2012.

SANTOS, Fátima Sibelli Monteiro Nascimento Santos. Da Obrigatoriedade de Intervenção da Fundação Nacional do Índio nos processos de colocação de crianças e jovens indígenas em famílias substitutas. Conteúdo Jurídico. Brasília-DF: 23 dez. 2014. Disponível em: <http://www.conteudojuridico.com.br/?artigos\&ver=2.51684>. Acesso em: 08 nov. 2017.

STJ - SUPERIOR TRIBUNAL DE JUSTIÇA. Recurso Especial n. 1566808/MS. Recorrente: A.V. Recorrido: Ministério Público do Estado de Mato Grosso do Sul. Relator: Min. Marco Aurélio Bellizze. Brasília, 19 set. 2017. DJe 02 out. 2017.

TJMS - TRIBUNAL DE JUSTIÇA DO MATO GROSSO DO SUL. Agravo de Instrumento n. 40135347920138120000/MS. Agravante: Sinforiana Rosana Silva. Recorridos: Jaime Moreira filho e outro. Relator: Des. Divoncir Schreiner Maran. Campo Grande, 25 mar. 2014. DJ 07 abr. 2014.

VILLARES, Luiz Fernando. Direito e povos indígenas. Curitiba: Editora Juruá, 2013.

VITORELLI, Edilson. Estatuto do Índio: Lei 6.001/1973. 3. Ed. rev., ampl. e atual. Salvador: Editora Juspodium. 2016. 